\title{
Maxillofacial Prosthesis: A Review of Treatment Concepts for Better Prosthesis Prognosis
}

\section{Sanjay Prasad ${ }^{1}$}

\section{ABSTRACT}

Maxillofacial prosthesis currently finds itself experiencing more change than at any other time over past 50 years of its recognized existence. Rehabilitation of facial defect, either congenital or acquired, is a difficult challenge for the surgeon as well as prosthodontist. The prosthodontist is limited by the properties of the materials available for facial restorations, the mobility of soft tissue surrounding the defects, the difficulty of establishing retention for large prosthesis, and the patient ability to accept the outcome. However, the acceptance of prosthesis recently has improved remarkably due to better coordination between surgeon and prosthodontist and introduction of dental implant which has dramatically improved the retention and esthetic that result from accurate and repeatable positioning of the implant, and the ease of maintenance. Dramatic improvement in the acceptance of prosthesis is seen if the prosthodontist participation can begin early in the course of patient care which ultimately will increase the quality of life $(Q \circ L)$ of the patient.

$\underline{\text { Keywords }}$

Maxillofacial Prosthesis; Surgeon; Prosthodontics; Dental Implants; Quality of Life

$\mathrm{M}$ axillofacial prosthetics is a subspecialty of prosthodontics that involves rehabilitation of patients with defects or disabilities that were present when born or developed due to disease or trauma. Maxillofacial prosthodontics are accustomed to working co-operatively with ENTs, Oral Surgeons, Neurologists, Radiation Oncologists, Speech Pathologists, Anaplastologists, and various ancillary personnel. The overall goal of all maxillofacial prosthetic treatment is to improve the quality of life. Some common examples of prosthetic treatment are:

\section{A) EXTRA ORAL PROSTHESIS}

(i) Ocular Prosthesis (Replaces Eyes)

(ii) Orbital Prosthesis (Replaces Eyes \& Surrounding tissues)

(iii) Auricular Prosthesis (Replaces Ear)

(iv) Nasal prosthesis (Replaces Nose)

(v) Mid facial prosthesis (replaces part of the face)

(vi) Somatic prosthesis (replaces a body part like fingers, hands, etc.)

(vii) Radiation shield

\section{B) INTRA ORAL}

(i) Immediate or surgical obturator ${ }^{1}$ : Supports the surgical packing in resection cavity (Figs. 1a, 1b)

(ii) Interim obturator ${ }^{2}$ : Restores teeth and gums and has an extension which causes the defect to close.

(iii) Definitive obturator: Delivered after complete healing and remodeling to tissue.

(iv) Palatal lift prosthesis: Helps soft palate assume correct position for speech.

(v) Palatal augmentation (drop) prosthesis: Alter palate prosthetically for speech.

(vi) Mandibular Resection Prosthesis

(vii) Fluoride carrier: Helps to strengthen, protect and preserve compromised teeth.

Among all the above prosthesis discussed, the maxillary

1 - Department of Prosthetic Dentistry, Dr R Ahmed Dental College and Hospital, Kolkata

Corresponding author:

Dr Sanjay Prasad

email: drsanjay1@gmail.com 
defect prosthesis is most frequently constructed and it presents an unlimited variety of possible configuration. Surgical defects were most frequent type of maxillary defect seen accounting for $89.5 \%$ of the case while congenital and traumatic defects accounted for 5.3\% each. ${ }^{3}$ Malignant tumors were main indication for surgery $(76.5 \%)$ of which squamous cell carcinoma constituted $84.6 \%$ and adenocystic carcinoma (15.4\%).

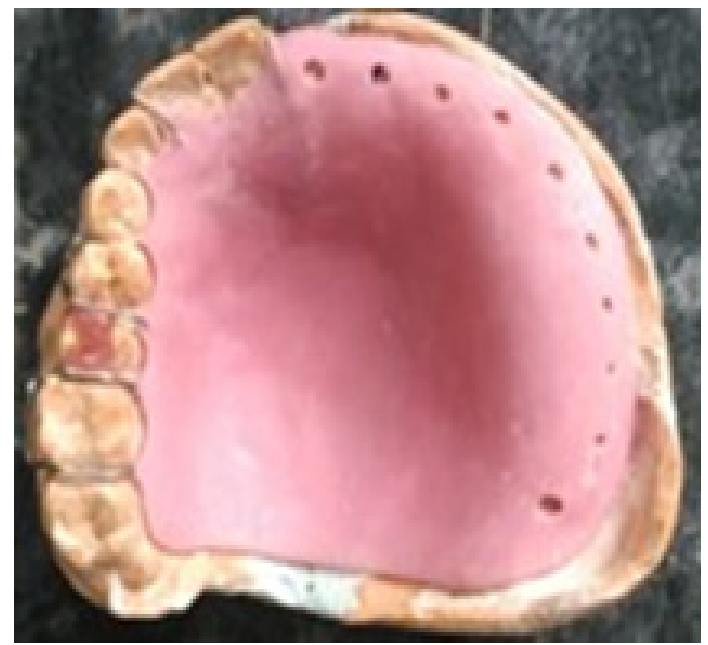

Fig.1.a: Surgical obturator placed on cast with holes for fixation.

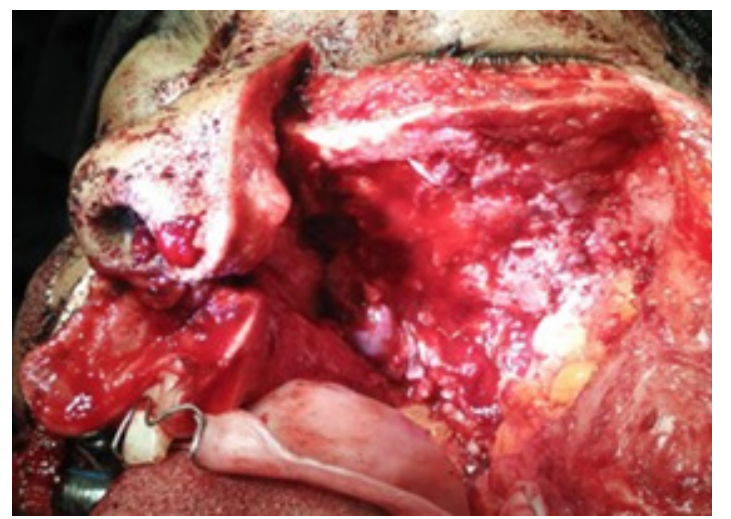

Fig.1.b: Surgical obturator placed in mouth after resection.

If properly planned the rehabilitation of maxillary defect is so effective that reconstructive surgery is not needed. However in total palatectomy defect surgical reconstruction followed by placement of dental implant and dental implant retained prosthesis is required.

Prosthodontist face many challenges and the main objectives $^{4}$ are:

1. To restore the function: Speech, respiration, chewing, and deglutition.

2. To restore the form: Facial appearance.

3. Separation between oral and nasal cavities to restore normal function of speech, respiration, and deglutition. 4. To provide support to the soft tissue to restore the mid-facial contour and an acceptable aesthetic results.

5. To provide support for the orbital contents to prevent ophthalmic complications such as enophthalmos and diplopia.

The challenges faced by the prosthodontist can be better managed if pre-surgical planning and coordination with concerned surgeon is executed properly keeping in mind the final restoration of defect. Some alterations at surgery to enhance the prosthetic prognosis are as follows: ${ }^{5}$

1.(i) Skin grafting the defect- In radical maxillectomy defects skin grafting the inside of the check flap creates a divergent lateral wall which when engaged by the obturator prosthesis, facilities retention, stability and support. The non-skin lined surface epithelializes spontaneously and is lined with poorly keratinized epithelium ${ }^{6}$ which is not suitable to engage the obturator and withstand the abrasion trauma associated with obturator use. (Fig. 2)

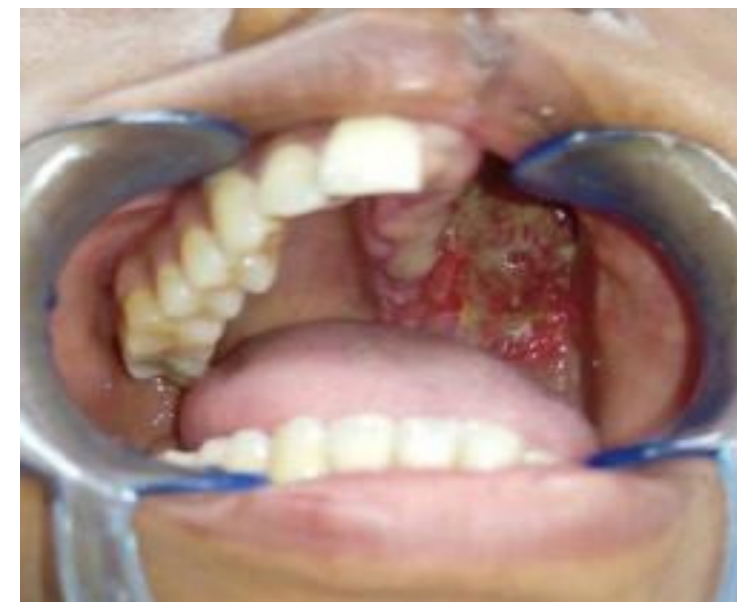

Fig.2: Non skin lined defect showing poorly keratinized epithelium not suitable for prosthesis engagement.

(ii) The scar band at the skin graft mucosal junction creates an undercut superior to this junction. Engagement of the undercut with obturator prosthesis facilitates 
retention on the defect side.

(iii) Skin lined defects provide keratinized surface in the defect that can be engaged more aggressively with the prosthesis thereby improving stability, retention and support for the obturator prosthesis.

2. Large defects should not be closed surgically and access to the defect should be maintained to be restored by obturator fabrication.

3. While resecting maxilla effort should be made to preserve the premaxilla. Retaining premaxilla on the defect side allows for more favorable obturator design which helps in improved retention, stability and patient compliance. (Fig.3)

Fig.3: Effort should be to preserve the premaxilla region.

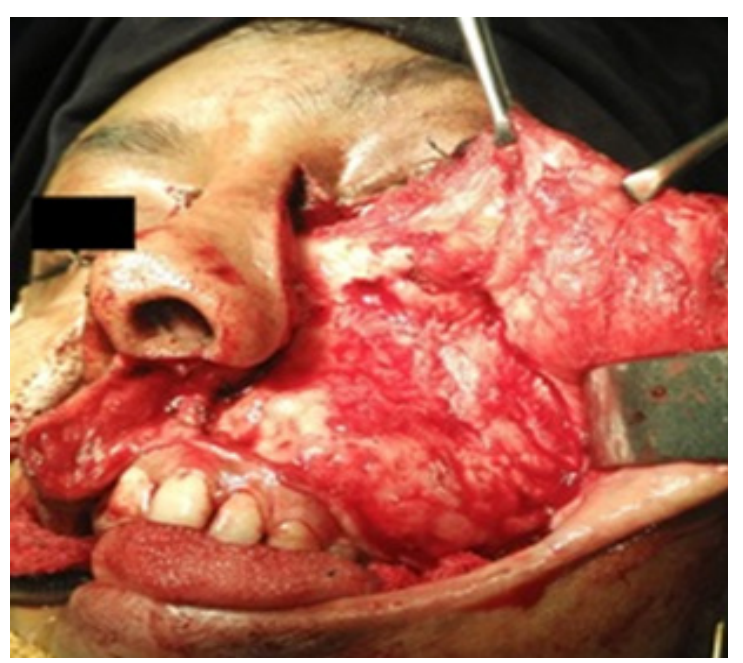

Fig.4: Sufficient amount of bone present around the abutment tooth.

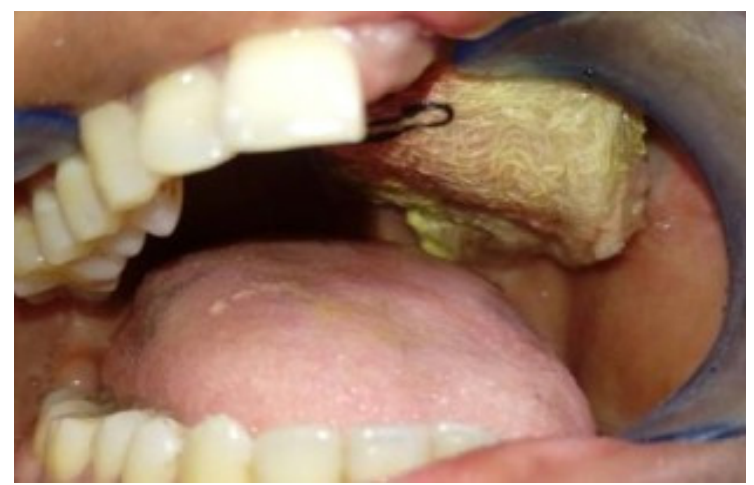

4. Abutment teeth adjacent to the defect are subjected to the greatest stress and bony cuts through the alveolus to these teeth should be interproximal rather than intraseptal to preserve sufficient amount of bone around the tooth. ${ }^{7}$ (Fig.4)

5. Soft palate resection- Middle third of the soft palate is responsible for palate elevation (levator veli palatini) during velopharyngeal closure. In partial edentulous patients when the middle third is resected for tumour control the remaining posterior third should also be resected. This will ensure appropriate access to the residual velopharyngeal musculature.

6. Placement of dental implants can have a dramatic effect on the function of the maxillofacial prosthesis. ${ }^{8,9}$ Masticatory performance may be restored to presurgical levels in some patients ${ }^{10}$ and with improved retention of the obturator prosthesis, speech and swallowing should be more efficient.

The forms of maxillofacial prosthesis are divided broadly into 4 categories ${ }^{11}$ :

(i) the maxillofacial prosthesis of solid obturator

(ii) maxillofacial prosthesis with open type obturator

(iii) Maxillofacial prosthesis with open type obturator with removable lid

(iv) Maxillofacial with hollow obturator.(Figs.5a,5b) (Table:I)

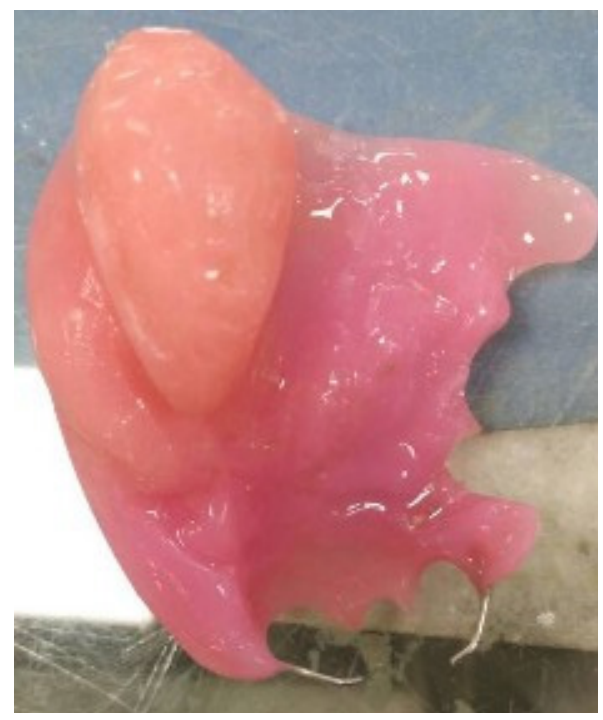

Fig.5.a: Hollow bulb obturator 
Table I: A comparative evaluation of each form of obturator

\begin{tabular}{|c|l|l|l|}
\hline \multicolumn{1}{|c|}{$\begin{array}{c}\text { FORM OF } \\
\text { OBTURATOR }\end{array}$} & \multicolumn{1}{|c|}{ FEATURE OF FORM } & ADVANTAGES & DISADVANTAGES \\
\hline Solid obturator & $\begin{array}{l}\text { The entire obturator is fabricated of resin } \\
\text { used mainly for small defects }\end{array}$ & Easy Fabrication & Weight is greater \\
\hline Hollow obturator & $\begin{array}{l}\text { The inside is hollowed out to lightening } \\
\text { the weight of the obturator. Conventional } \\
\text { method }\end{array}$ & $\begin{array}{l}\text { Lighter in weight } \\
\text { than solid obturator }\end{array}$ & $\begin{array}{l}\text { Water and conta- } \\
\text { minants may invade } \\
\text { the inside time } \\
\text { consuming }\end{array}$ \\
\hline $\begin{array}{l}\text { Open type obturator } \\
\text { The upper section of the obturator is open }\end{array}$ & $\begin{array}{l}\text { Light weight, Easier } \\
\text { to insert.Cleaning is } \\
\text { simple }\end{array}$ & $\begin{array}{l}\text { Water and food debris } \\
\text { may accu-mulate in } \\
\text { the obturator }\end{array}$ \\
\hline $\begin{array}{l}\text { Open type obturator } \\
\text { with removable lid. }\end{array}$ & $\begin{array}{l}\text { The top of the open type obturator has a } \\
\text { detachable lid }\end{array}$ & $\begin{array}{l}\text { Periodic cleaning } \\
\text { keeps the interior } \\
\text { clean }\end{array}$ & Increase in weight \\
\hline
\end{tabular}

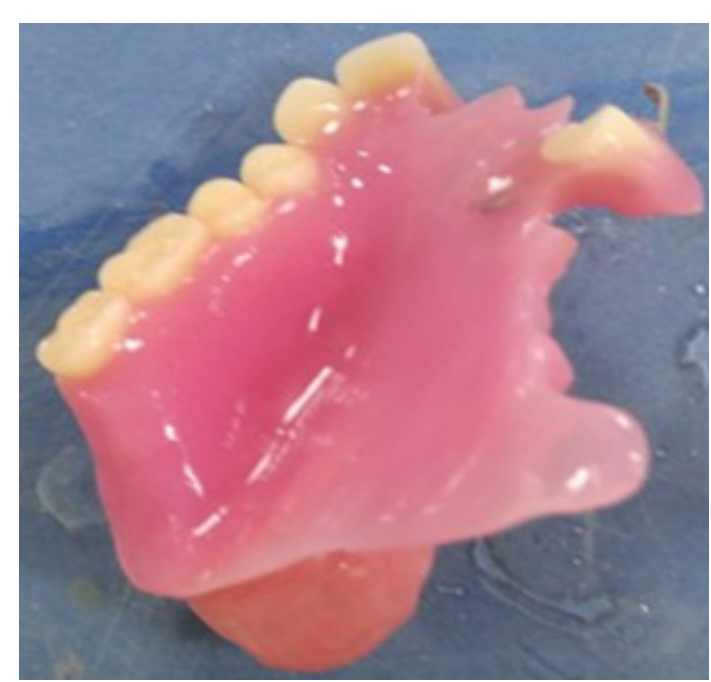

Fig.5.b: Hollow bulb obturator

\section{Conclusion}

Rehabilitation of patients with disabilities of the head and neck secondary to acquired and congenital defects is a difficult task, requiring close interaction among a number of heath science disciplines. Post surgical defects predispose the patient to hypernasal speech, leakage of food bolus and liquids into nasal cavity, impaired mastication and in some case various degrees of cosmetic deformity. Prosthetic techniques can provide excellent rehabilitation for patients with oral-facial defects.

With the advent of computer aided design and manufacturing technologies, new surgical and prosthodontic techniques are evolving, when properly executed in a multidisciplinary environment, these methods provide patients with implant supported prosthesis that very effectively and predictably restore form and function. It can bring smile to the despondent patients shooting out their psychological problems aside and bringing them back for daily routine work in the society.

\section{References}

1. Lang BR, Bruce RA. Pre surgical maxillectomy prosthesis. J Prosthet Dent. 1967;17:613-9

2. Jacob R, Martin J, King G. Modification of surgical obturator in interim prosthesis. J. Prosthet Dent. 1989; 62: 619-21

3. Omo J, Sede M, Enabulele J. Prosthetic Rehabilitation of Patients with Maxillary Defects in a Nigerian Tertiary Hospital. Annals of Medical and Health Sciences Research 2014; 4(4):630-3. doi:10.4103/2141-9248.139352

4. Chalian VA, Drane JB, Standish SM. Maxillofacial prosthetics. Multidisciplinary practice. United states. The William \& Wilkins Company, 1972 p 133-48 
5. Beumer J, Nishimura R, Roumanas E. Maxillary defects: Alteration at surgery which enhance the prosthetic prognosis In: Zlotolow I, Esposito S, Beumer J (eds). Proceeding of the First international congress and Maxillofacial Prosthetics New York: Memorial Sloan Kettering Cancer Center. 1995: 22-26

6. Buemer III John, Marunick Mark T, Esposito Salvatore J. Maxillofacial rehabilitation.ed3.Quintessence Publishing Co Inc.U.S.2011. p 161-2

7. Lyons KM, Beumer J, Caputo A. Abutment load transfer by removable partial denture obturator framework in different acquired maxillary defects. J. Prosthet Dent. 2005: 94: 281-8

8. Roumanas E, Nishimura R, Davis B, Beumer J III. Clinical evaluation of implants retaining maxillary obturator prosthesis. J Prothet Dent. 1997; 77: 184-90

9. Nilmi A, Ueda M, Kaneda T. Maxillary obturator supported by osseointegrated implants placed in irradiated bone: Report of cases. J Oral Maxillofac Surg. 1993; 51: 804-9

10. Garrett N. Outcome of maxillectomies with conventional and implant restorations. Presented at the international congress on Maxillofacial Rehabilitation, Bangkok, Thailand 24-27 Sept 2008

11. Kan-ichi Seto, Matsuura M, Shimazato K, Goto M, Namura T. Atlas of oral and Maxillofacial Rehabilitation, Quintessence Publication Co. Ltd. 2003 p. 29-30. 